\title{
Metabolic engineering of Corynebacterium glutamicum for producing branched chain amino acids
}

\author{
Shengzhu Yu ${ }^{\dagger}$, Bo Zheng ${ }^{\dagger}$, Zhenya Chen ${ }^{*}$ (I) and Yi-Xin Huo
}

\begin{abstract}
Background: Branched chain amino acids (BCAAs) are widely applied in the food, pharmaceutical, and animal feed industries. Traditional chemical synthetic and enzymatic BCAAs production in vitro has been hampered by expensive raw materials, harsh reaction conditions, and environmental pollution. Microbial metabolic engineering has attracted considerable attention as an alternative method for BCAAs biosynthesis because it is environmentally friendly and delivers high yield.

Main text: Corynebacterium glutamicum (C. glutamicum) possesses clear genetic background and mature gene manipulation toolbox, and has been utilized as industrial host for producing BCAAs. Acetohydroxy acid synthase (AHAS) is a crucial enzyme in the BCAAs biosynthetic pathway of C. glutamicum, but feedback inhibition is a disadvantage. We therefore reviewed AHAS modifications that relieve feedback inhibition and then investigated the importance of AHAS modifications in regulating production ratios of three BCAAs. We have comprehensively summarized and discussed metabolic engineering strategies to promote BCAAs synthesis in C. glutamicum and offer solutions to the barriers associated with BCAAs biosynthesis. We also considered the future applications of strains that could produce abundant amounts of BCAAs.
\end{abstract}

Conclusions: Branched chain amino acids have been synthesized by engineering the metabolism of C. glutamicum. Future investigations should focus on the feedback inhibition and/or transcription attenuation mechanisms of crucial enzymes. Enzymes with substrate specificity should be developed and applied to the production of individual BCAAs. The strategies used to construct strains producing BCAAs provide guidance for the biosynthesis of other high valueadded compounds.

Keywords: Corynebacterium glutamicum, BCAAs biosynthesis, Metabolic engineering, Feedback inhibition, Acetohydroxy acid synthase

\section{Introduction}

Branched chain amino acids (BCAAs), including L-valine, $\mathrm{L}$-leucine, and L-isoleucine, are essential amino acids [1, 2] that are widely used in the food [3], pharmaceutical

\footnotetext{
*Correspondence: chenzhenya@bit.edu.cn

†Shengzhu Yu and Bo Zheng contributed equally to this work

Key Laboratory of Molecular Medicine and Biotherapy, School of Life Science, Beijing Institute of Technology, No. 5 South Zhongguancun

Street, Haidian District, Beijing 100081, China
}

$[4,5]$, and animal feed [6] industries. The global market for BCAAs during 2020 was USD 233 million, and this is likely to reach USD 303 million by the end of 2026, due to a compound annual growth rate of $3.80 \%$ [7]. The market proportions of valine, leucine, and isoleucine are, respectively, $48 \%, 34 \%$, and $18 \%$ [8]. Generally, the consumption of a leucine to isoleucine to valine ratio of 2:1:1 before, during, or after training to initiate muscle protein synthesis, increase energy, and reduce fatigue has dominated the market (87.1\%) [9]. Increasing demand for original author(s) and the source, provide a link to the Creative Commons licence, and indicate if changes were made. The images or other third party material in this article are included in the article's Creative Commons licence, unless indicated otherwise in a credit line to the material. If material is not included in the article's Creative Commons licence and your intended use is not permitted by statutory regulation or exceeds the permitted use, you will need to obtain permission directly from the copyright holder. To view a copy of this licence, visit http://creativecommons.org/licenses/by/4.0/. The Creative Commons Public Domain Dedication waiver (http://creativeco mmons.org/publicdomain/zero/1.0/) applies to the data made available in this article, unless otherwise stated in a credit line to the data. 
large amounts of BCAAs has driven the need for more rapid and efficient methods of production. Traditional BCAAs production methods mainly include chemical synthesis, protein hydrolysis, and enzymatic catalysis in vitro $[10,11]$. However, the raw materials for these methods are expensive, reaction conditions are harsh, and such reactions pollute the environment. Microbialbased metabolic engineering has recently emerged as an economical and practical tool for the production of highvalue compounds [12]. Compared with conventional methods, microbial-based metabolic engineering offers many advantages such as inexpensive raw materials, ecofriendly fermentation conditions, and high yield.

Gram-positive Corynebacterium glutamicum (C. glutamicum) is regarded as a model organism, thanks to an established genetic background and a corresponding mature gene manipulation toolbox [13]. It is also generally regarded as safe (GRAS) [14]. Thus, C. glutamicum has served as a host for producing industrial-scale medicines, as well as bulk and food-grade chemicals. Food-grade glutamic acid, lysine, and BCAAs have been biosynthesized by $C$. glutamicum using various strategies $[6,15,16]$. Traditional C. glutamicum strains have produced industrial amounts of BCAAs via random mutagenesis and screening. However, random mutations in the C. glutamicum genome can result in physiological changes, growth stagnation, and the accumulation of toxic by-products [6]. The desirable properties induced by random mutations could not be sustained over multiple generations, which resulted in a decreased capacity for producing BCAAs. Therefore, strains were needed that could stably generate industrial quantities of BCAAs.

Generally, rationally designed host strains achieve stable performance and generate good-quality products. Based on its genetic background and its mature gene manipulation toolbox, C. glutamicum has been rationally engineered to boost BCAAs production. Acetohydroxy acid synthase (AHAS) is a crucial enzyme in the $C$. glutamicum BCAAs biosynthetic pathway, but it is susceptible to feedback inhibition by BCAAs [17]. The many modifications of this enzyme and their corresponding effects are summarized and reviewed herein. We analyzed the importance of AHAS modification to production ratios of L-valine, L-leucine, and L-isoleucine. We then considered a possible catalytic mechanism of AHAS and investigated the future directions of AHAS modifications. We also summarized other engineering strategies to enhance BCAAs production such as the overexpression or protein engineering of rate-limiting enzymes, knocking down or knocking out competing pathways, or regulating the balance of entire pathways. The advantages and disadvantages of each strategy are comprehensively discussed. Based on the outcomes of extant strategies, we suggest others that might further increase BCAAs production. We investigated future applications of highperformance strains in the biosynthesis of BCAAs derivatives, development of BCAAs biosensors, and a possible applicable regulation strategy.

\section{Metabolic pathways of BCAAs in C. glutamicum}

Figure 1 shows the biosynthetic pathways of BCAAs in C. glutamicum. L-valine, L-leucine, and L-isoleucine are all derived from the central metabolite, pyruvate. Their production pathways share crucial enzymes such as acetohydroxy acid synthase (AHAS), acetohydroxy acid isomeroreductase (AHAIR), dihydroxy acid dehydratase (DHAD), and aminotransferase (TA). Two pyruvate molecules are catalyzed by AHAS to produce 2-acetolactate, which is sequentially catalyzed by AHAIR and DHAD to produce 2-ketoisovalic acid (2-KIV). Aminotransferase subsequently catalyzes 2 -KIV to L-valine. Isopropyl malate synthase (IPMS) competes with TA for 2-KIV and catalyzes 2-KIV to 2-isopropylmalate, which is then sequentially converted to 2-ketoisocaproate by $\alpha$-isopropylmalate isomerase (IPMI) and $\alpha$-isopropylmalate dehydrogenase (IPMD). Thereafter, 2-ketoisocaproate is catalyzed by TA to generate L-leucine. Oxaloacetate derived from phosphoenolpyruvate or pyruvate undergoes multi-step enzymatic catalysis to produce L-threonine, which is catalyzed by threonine dehydratase (TD) to 2-ketobutyrate, which along with pyruvate, is catalyzed by AHAS to generate 2-aceto-2-hydroxybutyrate that is sequentially catalyzed by AHAIR, DHAD, and TA to biosynthesize L-isoleucine.

Feedback derived from L-valine, L-leucine, or L-isoleucine accumulation inhibits AHAS activity [18], the expression of which is regulated by transcriptional attenuation of these amino acids. Furthermore, TD activity is inhibited by feedback derived from L-isoleucine accumulation [19]. The activity and expression of IPMS are, respectively, regulated by leucine feedback inhibition and leucine transcription attenuation [20]. L-threonine accumulation inhibits the activity of enzymes homoserine kinase (HK), homoserine dehydrogenase (HD), and aspartate kinase (AK), which participate in L-threonine biosynthetic pathway [21]. The transport proteins BrnFE and BrnQ are, respectively, responsible for transporting BCAAs from cells into the extracellular milieu and viceversa. The expression of BrnFE is positively regulated by the global transcription factor Lrp.

\section{Modification of AHAS to enhance BCAAs production}

Properties and catalysis of AHAS

Acetohydroxy acid synthase plays significant roles in the BCAAs biosynthetic pathway by inducing the crucial 


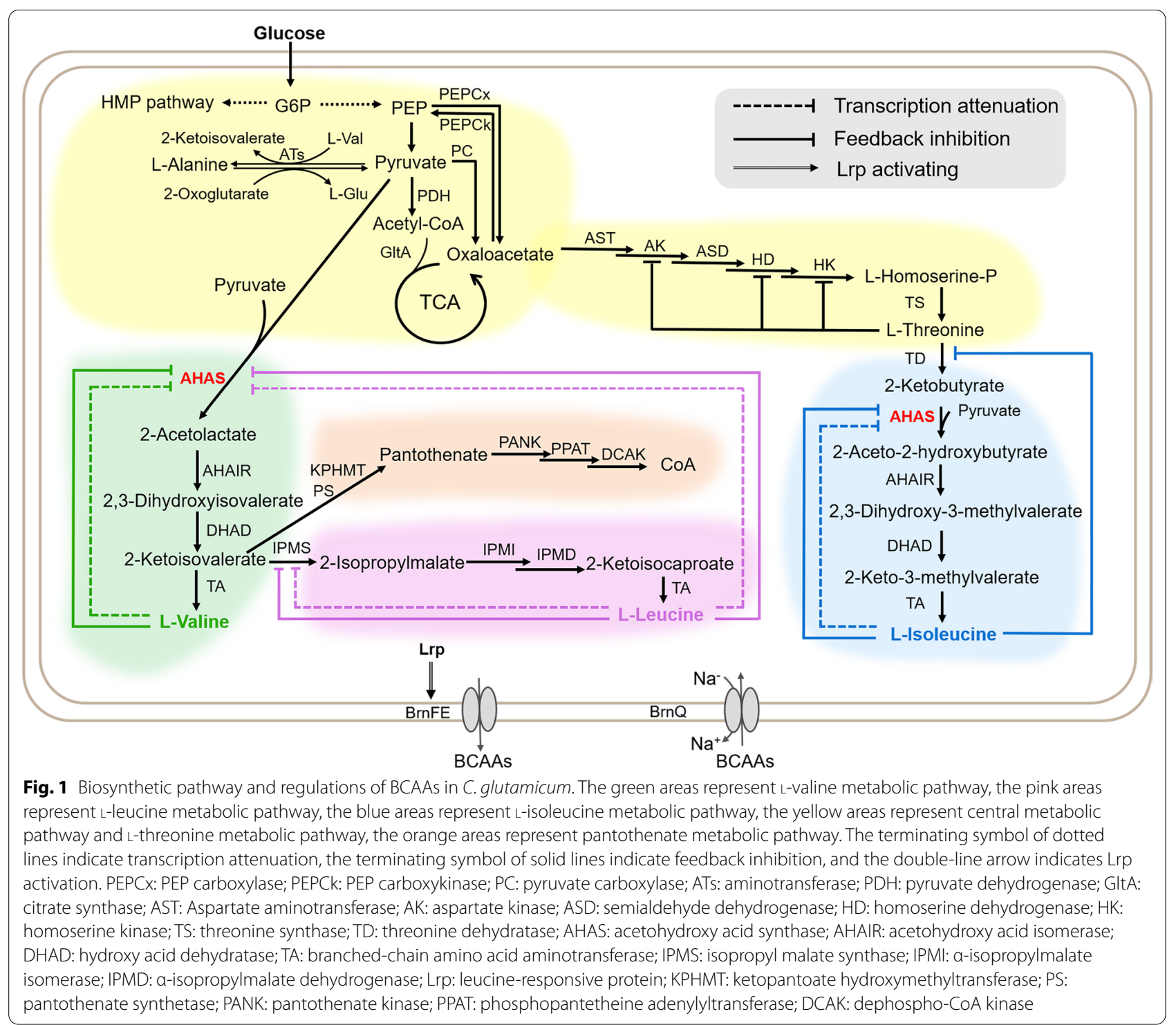

catalysis of two pyruvate molecules to produce 2-acetolactate, and that of 2-ketobutyrate and pyruvate to generate 2-aceto-2-hydroxybutyrate. The $k_{\text {cat }} / K_{\mathrm{m}}$ of AHAS is significantly higher towards 2-ketobutyrate and pyruvate than towards the original two pyruvate molecules [22]. Catalysis by AHAS requires thiamine pyrophosphate (ThDP), divalent metal ions, and flavin adenine dinucleotide (FAD), for which it has high affinity [23-25]. Thiamine pyrophosphate directly participates in the catalytic reaction of AHAS and combines with it to form the reaction intermediate, hydroxyethyl-ThDP.

Acetohydroxy acid synthase is a tetramer comprising two large $(\sim 60 \mathrm{kDa})$ catalytic and two small $(\sim 10-17 \mathrm{kDa})$ regulatory subunits $[26,27]$ that are encoded by $i l v B$ and $i l v N$, respectively [28]. The $i l v B N C$ operon contains the $i l v B$ and $i l v N$ genes [29] and the 15-amino-acid leading peptide ilvL (MTIIRLVVVTARRLP*) between the promoter and the expressed genes. The leading peptide can attenuate the transcription of $i l v B$ and $i l v N$ in the presence of BCAAs [30]. The catalytic subunit of AHAS is usually regulated by BCAAs binding to the regulatory subunit, which then inhibits the activity of AHAS [31]. The $\mathrm{IC}_{50}$ values of AHAS for L-valine, L-leucine, and L-isoleucine are 0.110, 0.790 and $0.410 \mathrm{~g} / \mathrm{L}$, respectively, indicating that $\mathrm{L}$-valine is the most powerful inhibitor of AHAS activity among these amino acids [32]. 


\section{Removing feedback inhibition and transcriptional attenuation of AHAS}

AHAS have been engineered to relieve or weaken the feedback inhibition and transcription attenuation of AHAS, with positive results. For example, the amino acids G-I-I at positions 20, 21, and 22 of the regulatory subunit ilvN have been mutated into D-D-F to generate the M13 mutant that resisted feedback inhibition by $1.17 \mathrm{~g} / \mathrm{L}$ L-valine, L-isoleucine, or L-leucine [27]. Thereafter, mutant M13 was introduced into C. glutamicum, which increased the leucine titer from $3.46 \mathrm{~g} / \mathrm{L}$ to $7.21 \mathrm{~g} / \mathrm{L}$ [33]. Site-directed mutagenesis at the conserved regions of $i l v N$, such as $\mathrm{A} 42 \mathrm{~V}, \mathrm{~A} 89 \mathrm{~V}$, or $\mathrm{K} 136 \mathrm{E}$ also improves AHAS resistance to BCAAs. The mutant A 42V/A 89V maintained $>93 \%$ activity in the presence of $1.27 \mathrm{~g} / \mathrm{L}$ BCAAs. Incorporating this mutant into the BCAAs biosynthetic pathway increased L-valine production from 1.95 to $10.1 \mathrm{~g} / \mathrm{L}$ [34]. In addition, truncating 53 amino acids from the $\mathrm{C}$-terminus of $i l v N$ generated a shorter AHAS that could maintain $90.8 \%$ activity in the presence of $0.590 \mathrm{~g} / \mathrm{L}$ exogenous L-valine [35].

Besides introducing mutations into the regulatory subunit, the catalytic subunit $i l v B$ has been mutated in an attempt to decrease the feedback inhibition of AHAS by BCAAs. For instance, $i l v B$ harboring the W503Q mutation increased L-leucine production to $3.40 \mathrm{~g} / \mathrm{L}$, which was 1.1 -fold more than that in wild-type $i l v B$. W503Q and T96S mutations in $i l v B$ resulted in a 1.2 -fold increase in the $\mathrm{L}$-valine titer $(3.40 \mathrm{~g} / \mathrm{L})$ compared with that in wild-type $i l v B$ [36]. Table 1 summarizes the AHAS modifications and their results.

Studies have so far partly addressed the feedback inhibition of BCAAs towards AHAS, and while BCAAs production has been somewhat improved, feedback inhibition was not completely eliminated. Therefore, AHAS still requires engineering using other strategies. For example, considering the non-conservative property of regulatory subunits, the regulatory subunit of C. glutamicum AHAS might be substituted with the regulatory subunit of Escherichia coli AHAS II, which has no feedback inhibition by L-valine and does not influence AHAS activity [6]. This engineered AHAS might be useful for L-valine production.

In addition to releasing feedback inhibition, increasing AHAS activity was also deemed important. The catalytic subunit of AHAS would be an appropriate modification target to improve AHAS activity because it catalyzes reactions. Future investigation might search for and compare significant regions or sites of AHAS in C. glutamicum with those of other species and then mutagenize them to boost AHAS activity. Combining modified regulatory and catalytic subunits might result in an AHAS mutant with powerful catalytic activity and resistance to feedback inhibition.

\section{Analyzing the significance of AHAS substrate specificity} Corynebacterium glutamicum AHAS catalyzes the condensation of two pyruvate molecules (3-3 addition reaction) in the L-valine and L-leucine biosynthetic pathways and of one molecule each of pyruvate and 2-ketobutyrate (3-4 addition reaction) in the L-isoleucine pathway [37]. Native AHAS from C. glutamicum displays higher affinity to 2-ketobutyrate than to pyruvate. Therefore, C. glutamicum is inclined to accumulate L-isoleucine, which is synthesized with a precursor of 2-ketobutyrate [22, 27]. In addition, native AHAS isozyme II from $E$. coli represents a 60-fold higher specificity for 2-ketobutyrate than for pyruvate [38]. The substrate promiscuity of AHAS results in the simultaneous production of three BCAAs, but other by-products are generated that redirect carbon flux and waste carbon sources. The end result is a decrease in target BCAAs production. The substrate selectivity of AHAS towards pyruvate or 2-ketobutyrate determines the production ratios of L-valine, L-leucine, and L-isoleucine. Fermentation products of the three BCAAs with suitable ratios might meet the needs of practical direct application to the food or feed industries. For example, the market has the greatest demand for a ratio of 2:1:1 ratio of L-leucine, L-isoleucine, and L-valine. However, the structure and performance similarity of these BCAAs hinder their separation and purification. Hence, modifying AHAS to produce individual

Table 1 Modification of AHAS for BCAAs production

\begin{tabular}{|c|c|c|c|c|}
\hline Host & Mutation sites of AHAS & $\begin{array}{l}\text { Titer of BCAAs (shake flask) } \\
\text { (g/L) }\end{array}$ & Substrate & References \\
\hline C. glutamicum ATCC13032 & G20D/I21D/I22F & L-Valine: 15.2 & Glucose & {$[27]$} \\
\hline C. glutamicum A-1 & $\begin{array}{l}\text { Truncating } 53 \text { amino acids from ilvN } \\
\text { C-terminus }\end{array}$ & L-Valine: 11.2 & Glucose & {$[35]$} \\
\hline C. glutamicum ATCC 14067 & $\mathrm{~A} 42 \mathrm{~V} / \mathrm{A} 89 \mathrm{~V}$ & L-Valine: 10.1 & Glucose & {$[34]$} \\
\hline C. glutamicum KCCM11201P & W503Q/T96S & L-Valine: 3.40 & Glucose & {$[36]$} \\
\hline C. glutamicum KCCM11662P & W503Q & L-Leucine: 3.40 & Glucose & [36] \\
\hline
\end{tabular}


BCAAs has significantly decreased the costs of isolation and purification.

\section{Regulation of metabolic flux of BCAAs production pathways}

\section{Regulation of central carbon metabolism}

Various strategies have been applied to direct a carbon source towards a target biosynthetic pathway to efficiently improve its metabolic flux and further enhance target compound production. More carbon sources can be introduced into BCAAs production pathways. Central metabolic pathways, including glycolysis, the TCA cycle, and the pentose phosphate pathway act as key nodes to balance cell growth and target compound production. Pyruvate generated by the glycolytic pathway is an important intermediate for powering cell growth and an essential precursor for BCAAs biosynthesis in $C$. glutamicum [39]. Hence, regulating pyruvate accumulation can redirect carbon sources for BCAAs biosynthesis. The amount of pyruvate accumulated depends on regulation of the expression of pyruvate metabolismrelated enzymes. For example, knocking out the aceE gene encoding pyruvate dehydrogenase (PDH), which converts pyruvate into the precursor for TCA cycle (acetyl-CoA), enhances pyruvate accumulation and increases the carbon flux to produce $\mathrm{L}$-valine. With $i l v B$ $N C E$ overexpression, C. glutamicum $\triangle a c e E$ can produce $22.8 \mathrm{~g} / \mathrm{L} \mathrm{L}$-valine through fed-batch fermentation in acetate medium [40]. Subsequently, the pqo gene encoding pyruvate/quinine oxidoreductase (Pqo) that catalyzes the conversion of pyruvate to acetate has been knocked out in C. glutamicum $\triangle a c e E$. This strain can accumulate $26.4 \mathrm{~g} / \mathrm{L} \mathrm{L}$-valine within $24 \mathrm{~h}$ [41]. In addition, replacing the native aceE promoter with the weak A16 promoter decreases the transcriptional level of aceE. This increased the fermentation yield of $\mathrm{L}$-valine from 0.071 to $0.241 \mathrm{~g} / \mathrm{g}$ glucose, with a corresponding valine titer of $10.5 \mathrm{~g} / \mathrm{L}$. The $p q o$ and $p p c$ genes were subsequently deleted in C. glutamicum/aceE $A 16$ to reduce pyruvate flowing into the synthetic pathways of other compounds; this strain produced $\sim 86.5 \mathrm{~g} / \mathrm{L}$ L-valine after fed-batch fermentation [42]. Moreover, knocking out pyc in C. glutamicum to reduce pyruvate flowing into the TCA cycle increased the production of $\mathrm{L}$-valine and L-leucine from 5.93 to 6.74 and 15.7 to $16.9 \mathrm{~g} / \mathrm{L}$, respectively [43]. Citrate synthase (GltA) in C. glutamicum catalyzes the entry of acetylCoA into the TCA cycle. Substituting the native gltA promoter with a weaker promoter $\mathrm{P}_{\text {dapA-L1 }}$, decreases GltA activity by $16 \%$ and increases L-leucine production to $6.82 \mathrm{~g} / \mathrm{L}$ [33]. Replacing the native $a c e E$ and gltA promoters with the growth-regulated $\mathrm{P}_{\mathrm{CP} \_2836}$ promoter improved L-valine production at the stationary phase [44]. Table 2 summarizes these examples.
The above findings suggested that increasing pyruvate accumulation could efficiently enhance BCAAs production. So far, the main strategies applied to decrease central carbon metabolism consisted of knocking out crucial enzymes or replacing crucial enzyme promoters. One knockout method is $\lambda$-red homologous recombination, which can delete a single gene. In the future, CRISPR/ Cpf1 might be used to simultaneously knock out several genes (aceE, $p y c, p p c$, and $p q o$ ) by designing corresponding sgRNAs. The expression CRISPR/dCas9 or mutated Cpf1 might also be applied to partially or completely block the transcription of crucial enzymes to decrease their intracellular levels.

\section{Strengthening BCAAs biosynthetic pathways}

Enhancing the expression of enzymes involved in BCAAs biosynthetic pathways and weakening the interference of competing pathways are direct strategies that have been applied to centralize metabolic flux for BCAAs production. Table 3 shows the various methods used to strengthen BCAAs biosynthetic pathways and block competing pathways. For example, overexpression of the $i l v B N C D$ gene encoding AHAS, AHAIR, and DHAD in C. glutamicum ATCC13032 increased L-valine accumulation to $4.92 \mathrm{~g} / \mathrm{L}$. The panBC and $i l v A$ genes were subsequently knocked out to block competing D-pantothenate and L-isoleucine biosynthesis pathways, which further increased L-valine production to $10.7 \mathrm{~g} / \mathrm{L}$ [49]. Alanine aminotransferase (ATs) can compete with pyruvate to produce L-alanine in C. glutamicum [50]. Simultaneous aceE, alaT, and $i l v A$ knockout in C. glutamicum ATCC13869 resulted in a 44-fold increase in $\mathrm{L}$-valine production, and overexpressing $i l v B N C 1$ further improved L-valine production by $87.6 \%$ [45]. Moreover, the $i l v A$ and $l e u A$ promoters were modified to, respectively, decrease TD and IPMS expression; then, strong promoters overexpressed DHAD and TA, which ultimately increased L-valine production to $15.9 \mathrm{~g} / \mathrm{L}$ [51].

Deleting the IPMI and IPMD repressors and the competing pathways for L-isoleucine, L-alanine, D-pantothenate, and lactate production in C. glutamicum led to increased L-leucine production $(28.5 \mathrm{~g} / \mathrm{L})$. The subsequent overexpression of R529H/G532D/L535V IPMS in the knockout strain resulted in $38.1 \mathrm{~g} / \mathrm{L}$ L-leucine accumulation in a 50-L automated fermenter [64]. Moreover, C. glutamicum AN02 with G127D/I197V/ R529H/G561D IPMS, IPMI, and IPMD overexpression resulted in more leucine $(13.1 \mathrm{~g} / \mathrm{L})$ than a strain overexpressing only G127D/I197V/R529H/G561D IPMS [65]. Inserting the terminator with the strength of 40.4 a.u. before alaT and replacing native promoters of ilvBNC and leuA with the strong promoter $P_{t u f}$ improved L-leucine accumulation to $26.8 \mathrm{~g} / \mathrm{L}$ [43]. To address the 
Table 2 Regulation of central carbon metabolism in BCAAs producing strains

\begin{tabular}{|c|c|c|c|c|c|c|c|c|}
\hline Host & $\begin{array}{l}\text { Overexpression } \\
\text { genes }\end{array}$ & $\begin{array}{l}\text { Knockout } \\
\text { genes }\end{array}$ & $\begin{array}{l}\text { Titer of BCAAs } \\
\text { (shake flask) } \\
\text { (g/L) }\end{array}$ & $\begin{array}{l}\text { Titer of BCAAs } \\
\text { (fed batch) } \\
\text { (g/L) }\end{array}$ & $\begin{array}{l}\text { Productivity } \\
(g /(L \times h))\end{array}$ & $\begin{array}{l}\text { Yield } \\
\text { (g/g glucose) }\end{array}$ & Substrate & References \\
\hline $\begin{array}{l}\text { C. glutamicum } \\
\text { aceE A16 }\end{array}$ & $i l v B N C$, ilvE & $\Delta p q o, \Delta p p c$ & & L-Valine: 86.5 & 1.60 & 0.234 & Glucose & [42] \\
\hline $\begin{array}{l}\text { C. glutamicum } \\
\text { ATCC13869 }\end{array}$ & $i l v B N C$, Irp, brnFE & 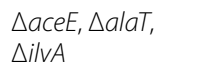 & L-Valine: 28.5 & L-Valine: 51.2 & 0.533 & 0.308 & Glucose & [45] \\
\hline $\begin{array}{l}\text { C. glutamicum } \\
\text { ATCC13032 }\end{array}$ & $i l v B N C$, ilvE & $\begin{array}{l}\triangle a c e E, \Delta p q o, \\
\Delta p g i\end{array}$ & & L-Valine: 48.0 & 0.656 & 0.488 & $\begin{array}{l}\text { Glucose, } \\
\text { acetate }\end{array}$ & [41] \\
\hline $\begin{array}{l}\text { C. glutamicum } \\
\text { ATCC13032 }\end{array}$ & $i l v B N C$, ilvE & DaceE & L-Valine: 12.3 & L-Valine 24.6 & 1.17 & 0.391 & $\begin{array}{l}\text { Glucose, } \\
\text { acetate }\end{array}$ & [40] \\
\hline $\begin{array}{l}\text { C. glutamicum } \\
\text { AN02 }\end{array}$ & & $\Delta P_{g \mid t A}: P_{C P \_2836}$ & L-Valine: 15.3 & & & 0.168 & Glucose & [44] \\
\hline $\begin{array}{l}\text { C. glutamicum } \\
\text { ATCC13032 }\end{array}$ & ilvBNC, ilvE & $\triangle a c e E, \Delta p q o$ & L-Valine: 12.4 & L-Valine 24.6 & & 0.150 & $\begin{array}{l}\text { Glucose, } \\
\text { acetate }\end{array}$ & [46] \\
\hline $\begin{array}{l}\text { C. glutamicum } \\
\text { ATCC13032 }\end{array}$ & ilvBNC, ilvE & $\begin{array}{l}\Delta p p c, \Delta p y c \\
I C D^{G 4075}\end{array}$ & L-Valine: 8.90 & & & 0.220 & Glucose & [47] \\
\hline $\begin{array}{l}\text { C. glutamicum } \\
\text { ATCC13032 }\end{array}$ & & $\begin{array}{l}\triangle p q o, \Delta p p c \\
\Delta a c e E, \triangle a l a T\end{array}$ & L-Valine: 2.64 & & & & Glucose & {$[48]$} \\
\hline $\begin{array}{l}\text { C. glutamicum } \\
\text { XQ-9 }\end{array}$ & ilvBNC, leuA & $\begin{array}{l}\Delta l t b R, \triangle p y c \\
\triangle a v t A, \text { inserting } \\
\text { terminator } \\
\text { before alaT }\end{array}$ & L-Leucine: 28.5 & & & & Glucose & [43] \\
\hline $\begin{array}{l}\text { C. glutamicum } \\
\text { ATCC13032 }\end{array}$ & $\begin{array}{l}\text { leuA } A^{R 529 H / G 532 D} \\
i^{\text {IVN }}{ }^{\mathrm{G} 20 \mathrm{D} / 121 \mathrm{D} / 122{ }^{\prime}}\end{array}$ & $\begin{array}{l}\Delta l t b R, \triangle l e u A, \\
\triangle i o / R \text {, replacing } \\
\text { gltA promoter } \\
\text { with } P_{\text {dapA-L1 }}\end{array}$ & L-Leucine: 6.82 & L-Leucine: 23.7 & 0.564 & 0.219 & Glucose & [33] \\
\hline
\end{tabular}

generation of by-products due to the substrate diversity of TA, the $i l v E$ gene encoding TA was knocked out, and aspartate aminotransferase (AspB) was overexpressed in C. glutamicum FA-1 [63]. That strain produced $82.6 \%$ more L-leucine $(20.8 \mathrm{~g} / \mathrm{L})$ than the original strain, while $\mathrm{L}$-valine production remained unaltered, indicating that AspB has higher specificity for the precursor of L-leucine than L-valine production [63].

Knocking out the alaT gene increased the L-isoleucine yield by $17.6 \%$ [61], and overexpressing TD, AK, $\mathrm{HD}$, and HK in C. glutamicum increased L-isoleucine production 7.6 -fold. The L-isoleucine biosynthetic pathway shares some initial steps with the L-lysine and L-methionine pathways, which leads to a shunt of the carbon flux. Based on that, knocking out the $d d h$ gene encoding 2,3-diaminopimelate dehydrogenase decreased L-lysine biosynthesis and allocated more carbon resources to L-isoleucine production; this generated an $8 \%$ increase in the L-isoleucine yield [60]. Genome promoters that have been mutated to increase TD and HD expression that is free of feedback inhibition and decrease the expression of dihydrodipicolinate synthase (DapA) have resulted in the accumulation of $6.95 \mathrm{~g} / \mathrm{L} \mathrm{L}$-isoleucine in shaker flasks [58].

\section{Removing feedback inhibition and transcriptional attenuation of other enzymes}

In addition to AHAS, relieving or removing the feedback inhibition and transcriptional attenuation of BCAAs, or intermediate metabolites of other crucial enzymes in C. glutamicum, can also alleviate obstacles in BCAAs biosynthetic pathways and further increase the production of corresponding BCAAs. Table 4 shows that introducing the Y553D mutation into IPMS relieved the feedback inhibition of IPMS by L-leucine and increased L-leucine production by 30 -fold compared with that in wild-type IPMS [66]. The leading peptide leuL (MTSRANLLLLRRGGSQRS*) [30] and the promoter of the leuA gene encoding IPMS have been replaced with the $\mathrm{P}_{\text {tuf }}$ promoter to remove the transcriptional attenuation of L-leucine towards IPMS in C. glutamicum and express IPMS (R529H/G532D IPMS) without feedback inhibition [33]. This ultimately resulted in a $50 \%$ increase in IPMS activity. Overexpressing R558H/G561D IPMS, which maintained 89\% activity towards $2 \mathrm{~g} / \mathrm{L}$ L-leucine, and replacing the native promoter $l e u A$ with PCJ7, which is free of transcriptional attenuation, increased L-leucine production 4.2-fold [67]. 
Table 3 Enhancement of BCAAs biosynthetic pathways

\begin{tabular}{|c|c|c|c|c|c|c|c|c|}
\hline Host & $\begin{array}{l}\text { Overexpression } \\
\text { genes }\end{array}$ & Knockout genes & $\begin{array}{l}\text { Titer of BCAAs } \\
\text { (shake flask) } \\
\text { (g/L) }\end{array}$ & $\begin{array}{l}\text { Titer of BCAAs } \\
\text { (fed batch) } \\
\text { (g/L) }\end{array}$ & $\begin{array}{l}\text { Productivity } \\
(g /(L \times h))\end{array}$ & $\begin{array}{l}\text { Yield } \\
\text { (g/g } \\
\text { glucose) }\end{array}$ & Substrate & References \\
\hline C. glutamicum R & $\begin{array}{l}\text { il } V B N^{G 156 E}, i l / C^{334 G /} \\
\angle 48 E / R 49 F, \text { ilVD, } \\
\text { leuDH }\end{array}$ & $\triangle l d h A$ & L-Valine: 227 & & 7.17 & 0.410 & Glucose & [52] \\
\hline $\begin{array}{l}\text { C. glutamicum R } \\
\text { JCM } 18229\end{array}$ & $\begin{array}{l}\text { ilvBNG156E, ilvC } C^{\mathrm{S} 34 \mathrm{G} /} \\
\text { L48E/R49F, illvD, } \\
\text { leuDH, gapA, pyk, } \\
\text { pfk, pgi, tpi }\end{array}$ & $\begin{array}{l}\triangle l d h A, \triangle p p c, \triangle p t a, \\
\triangle a c k A, \triangle c t f A \\
\triangle a v t A\end{array}$ & L-Valine: 150 & & & 0.573 & Glucose & [53] \\
\hline $\begin{array}{l}\text { C. glutamicum } \\
\text { ATCC13032 }\end{array}$ & $\begin{array}{l}\text { ilvN G20D/121D/122F, } \\
\text { replacing ilvD } \\
\text { promoter with } \\
\text { P-ilvDM7, replac- } \\
\text { ing ilvE promoter } \\
\text { with P-ilvEM6 }\end{array}$ & $\begin{array}{l}\triangle p a n B \text {, replacing } \\
\text { ilvA promoter } \\
\text { with P-ilvAM1CG }\end{array}$ & L-Valine: 15.9 & & & & Glucose & [51] \\
\hline $\begin{array}{l}\text { C. glutamicum } \\
\text { ATCC13032 }\end{array}$ & $i l V B N C, i l v D$ & $\triangle i l v A, \triangle p a n B C$ & L-Valine: 10.7 & & & & Glucose & [49] \\
\hline $\begin{array}{l}\text { C. glutamicum } \\
\text { YILW }\end{array}$ & brnFE & $\triangle b r n Q$ & & L-Isoleucine: 29.0 & & & Glucose & [54] \\
\hline $\begin{array}{l}\text { C. glutamicum } \\
\text { IWJ001 }\end{array}$ & gnd, fbp, pgl & & L-Isoleucine: 10.9 & L-Isoleucine: 29.0 & 0.345 & 0.138 & Glucose & {$[55]$} \\
\hline $\begin{array}{l}\text { C. glutamicum } \\
\text { WM001 }\end{array}$ & phaCAB & & L-Isoleucine: 9.58 & L-Isoleucine: 29.8 & & 0.129 & Glucose & {$[56]$} \\
\hline $\begin{array}{l}\text { C. glutamicum } \\
\text { JHI3-156 }\end{array}$ & Irp, brnFE & & L-Isoleucine: 3.49 & L-Isoleucine: 26.9 & 0.374 & 0.122 & Glucose & {$[57]$} \\
\hline $\begin{array}{l}\text { C. glutamicum } \\
\text { MH20-22B }\end{array}$ & $\begin{array}{l}\text { ilva }{ }^{\mathrm{V} 323 \mathrm{~A}} \text {, hom } \\
\mathrm{G}^{3} 8 \mathrm{E} \text {, introducing } \\
\text { the ilvA-con pro- } \\
\text { moter mutation, } \\
\text { replacing hom } \\
\text { promoter with } \\
\text { PcspB }\end{array}$ & $\begin{array}{l}\text { Introducing the } \\
\text { PdapA-C13 } \\
\text { promoter muta- } \\
\text { tion }\end{array}$ & L-Isoleucine: 6.95 & L-Isoleucine: 14.3 & 0.184 & 0.137 & Glucose & [58] \\
\hline $\begin{array}{l}\text { C. glutamicum } \\
\text { JHI3-156 }\end{array}$ & $z w f, p p n K$ & & L-Isoleucine: 4.10 & & 0.057 & 0.072 & Glucose & [59] \\
\hline $\begin{array}{l}\text { C. glutamicum } \\
\text { ATCC13869 }\end{array}$ & $\begin{array}{l}\text { lysC, hom, thrB, } \\
\text { ilvA }\end{array}$ & $\Delta d d h$ & L-Isoleucine: 3.81 & & & & Glucose & {$[60]$} \\
\hline $\begin{array}{l}\text { C. glutamicum } \\
\text { YILW }\end{array}$ & & $\Delta a l a T$ & L-Isoleucine: 2.09 & L-Isoleucine: 15.4 & & 0.136 & Glucose & {$[61]$} \\
\hline $\begin{array}{l}\text { C. glutamicum } \\
\text { XQ-9 }\end{array}$ & $\begin{array}{l}\operatorname{leuA}, \text { ilvBN, leuDH, } \\
\text { ilVC }^{S 34 G / / 48 E / R 49 F}, \\
\text { rocG }\end{array}$ & $\Delta l t b R, \Delta i l v E, \Delta g d h$ & L-Leucine: 23.3 & & & 0.191 & Glucose & {$[62]$} \\
\hline $\begin{array}{l}\text { C. glutamicum } \\
\text { FA-1 }\end{array}$ & $a \operatorname{spB}$ & $\triangle i / v E$ & L-Leucine: 20.8 & & & & Glucose & {$[63]$} \\
\hline
\end{tabular}

The activity of TD is, respectively, reduced by $85 \%$ and almost completely lost in the presence of 0.660 and $1.97 \mathrm{~g} / \mathrm{L}$ L-isoleucine [73]. The V323A TD [68] and H278R/L351S TD [19] mutants that are more resistant to feedback inhibition than the wild type, were created by site-directed mutagenesis to relieve the feedback inhibition of TD by L-isoleucine. The highly conserved site of TD has been targeted, and V140M, F383A, and V140M/ F383A TD mutants were created. The specific activity of V140M and V140M/F383A TD was 1.5-fold higher than that of wild-type TD. Thus, F383A TD increased the L-isoleucine titer from 0.470 to $0.730 \mathrm{~g} / \mathrm{L}$ [72].
L-threonine is a crucial intermediate in the pathway of L-isoleucine production, as it induces feedback inhibition of the enzymes AK, HD, and HK that are involved in $\mathrm{L}$-threonine production. $\mathrm{L}$-threonine inhibits HD and $\mathrm{HK}$ activity by binding to allosteric sites on AK and HD and inhibits the activity of HK by competing with native substrates for its active sites [74]. The mutants A279T AK and G379S HD created by site-directed mutagenesis completely and partially resisted the feedback inhibition of L-threonine, respectively [71]. The A20G mutation introduced into $\mathrm{HK}$ induces activity comparable with that in wild-type $\mathrm{HK}$ and substantial ability to resist feedback 
Table 4 Removing the feedback inhibition and transcriptional attenuation of other enzymes

\begin{tabular}{|c|c|c|c|c|c|c|c|}
\hline Host & Mutation sites & $\begin{array}{l}\text { Titer of BCAAs } \\
\text { (shake flask) } \\
\text { (g/L) }\end{array}$ & $\begin{array}{l}\text { Titer of BCAAs } \\
\text { (fed batch) } \\
\text { (g/L) }\end{array}$ & $\begin{array}{l}\text { Productivity }(g / \\
(L \times h))\end{array}$ & $\begin{array}{l}\text { Yield } \\
\text { (g/g } \\
\text { glucose) }\end{array}$ & Substrate & References \\
\hline $\begin{array}{l}\text { C. glutamicum } \\
\text { DSM8890 }\end{array}$ & V323ATD & L-Isoleucine: 16.4 & & & & Glucose & [68] \\
\hline C. glutamicum IWJ001 & $\begin{array}{l}\text { P176S/D426E/L575W } \\
\text { AHAS, F383VTD }\end{array}$ & L-Isoleucine: 5.83 & & & & Glucose & [69] \\
\hline C. glutamicum JHI3-156 & $\begin{array}{l}\text { P176S/D426E/L575W } \\
\text { AHAS, F383VTD }\end{array}$ & L-Isoleucine: 5.77 & L-Isoleucine: 30.7 & 0.426 & 0.120 & Glucose & [70] \\
\hline $\begin{array}{l}\text { C. glutamicum } \\
\text { ATCC13869 }\end{array}$ & $\begin{array}{l}\text { A279T AK, G378S HD, } \\
\text { F383V TD }\end{array}$ & L-Isoleucine: 3.53 & & & & Glucose & [71] \\
\hline $\begin{array}{l}\text { C. glutamicum } \\
\text { ATCC14067 }\end{array}$ & V140M/F383A TD & L-Isoleucine: 0.73 & & & & Glucose & [72] \\
\hline C. glutamicum ML1-9 & $\begin{array}{l}\text { R529H/G532D/L535V } \\
\text { IPMS }\end{array}$ & & L-Leucine: 38.1 & 0.794 & & Glucose & [64] \\
\hline $\begin{array}{l}\text { C. glutamicum } \\
\text { KCCM11662P }\end{array}$ & R558H/G561D IPMS & L-Leucine: 13.1 & & & & Glucose & [67] \\
\hline $\begin{array}{l}\text { C. glutamicum } \\
\text { ATCC13032 }\end{array}$ & $\begin{array}{l}\text { G20D/I21D/I22F AHAS, } \\
\text { R529H/G532D IPMS }\end{array}$ & L-Leucine: 6.82 & L-Leucine: 23.7 & 0.564 & 0.219 & Glucose & [33] \\
\hline $\begin{array}{l}\text { C. glutamicum } \\
\text { ATCC } 13032\end{array}$ & Y553D IPMS & L-Leucine: 1.55 & & & & Glucose & {$[66]$} \\
\hline
\end{tabular}

inhibition by L-threonine. Meanwhile, this mutant has a 5.3-fold lower Ki than the wild type. Structural analysis of $\mathrm{HK}$ revealed that changes in the van der Waals forces in A20G HK affected the affinity of L-threonine for active sites [74]. Based on this, AK, HD, and HK expressed without feedback inhibition in C. glutamicum have contributed to increased yields of L-lysine, L-threonine, and L-isoleucine [60]. Site-directed mutagenesis has achieved the efficient release of feedback inhibition that further enhanced BCAAs yields.

\section{Improving the supply of cofactors for crucial enzymes}

Balancing the intracellular reducing power derived from $\mathrm{NADH}$ and NADPH is significant for maintaining cell homeostasis and biosynthesizing target compounds. The cofactor NADPH is essential for the enzymes, ASD, HD, AHAIR, and TA, which are involved in BCAAs biosynthetic pathways $[75,76]$. The absence of nicotinamide nucleotide transhydrogenase complicates the reversible conversion of NADH to NADPH in C. glutamicum $[77,78]$, leading to a limited supply of NADPH and further affecting BCAAs production. Therefore, increasing the supply of NADPH to reinforce crucial enzyme reactions is a key step in improving BCAAs production. Two pathways can be used to produce NADPH. One is via the NAD $(\mathrm{H})$ kinase catalysis of $\mathrm{NAD}^{+}$and/or NADH to produce $\mathrm{NADP}^{+}$and/or NADPH $[79,80]$, and the other is via the dehydrogenase catalysis of $\mathrm{NADP}^{+}$to produce NADPH [81]. The glucose-6-phosphate (G6PD) and 6-phosphogluconate (6PGDH) dehydrogenases in $C$. glutamicum are mostly derived from the pentose phosphate pathways [82]. Therefore, the NAD kinase Ppnk has been overexpressed in a strain that increased $\mathrm{L}$-isoleucine production to $32.4 \mathrm{~g} / \mathrm{L}[69,70]$. Co-expressing Ppnk with G6PD improved the L-isoleucine yield by $85.9 \%$ [59]. Furthermore, enhancing the pentose phosphate pathway by overexpressing 6PGDH, 6-phosphogluconolactonase (PGL), and 1,6-bisphosphatase (FBPase) increased the L-isoleucine titer from 6.60 to $10.9 \mathrm{~g} / \mathrm{L}$ in shaker flasks [55].

Switching NADPH-dependent to NADH-dependent reactions is an alternative approach because the supply of NADH in C. glutamicum is sufficient for NADHdependent reactions to proceed. To convert AHAIR and TA into NADH-dependent enzymes in C. glutamicum, AHAIR was modified by introducing the S34G/L48E/ $\mathrm{R} 49 \mathrm{~F}$ mutations and replacing TA with leucine dehydrogenase (LeuDH) from Lysinibacillus sphaericus. The engineered strain produced $227 \mathrm{~g} / \mathrm{L}$ L-valine by overexpressing AHAS free of feedback inhibition [52]. Subsequently, NADH-dependent AHAIR was integrated with AHAS free of feedback inhibition into the genome of a C. glutamicum strain with an enhanced glycolysis pathway and deleted pathways of biosynthetic by-products to achieve an $\mathrm{L}$-valine yield of $150 \mathrm{~g} / \mathrm{L}$ [53]. In addition, the overexpression of NADH-dependent AHAIR, LeuDH from Lysinibacillus sphaericus, and glutamate dehydrogenase (GDH) from Bacillus subtilis in C. glutamicum XQ-9 $\Delta l t b R / l e u A i l v B N C$ increased L-leucine production to $23.3 \mathrm{~g} / \mathrm{L}$ [62]. 
Overexpression of crucial enzymes and deletion of competing pathways have been focused upon to strengthen BCAAs biosynthetic pathways. Replacing native promoters to increase or decrease target enzyme expression can also enhance the metabolic flux of BCAAs biosynthetic pathways. The strategies described above were based on published studies. Elucidation of the details of BCAAs biosynthetic pathways still requires a deep and comprehensive analysis. A dynamic metabolic network should be constructed, and a real-time monitoring system should be adopted to identify other ratelimiting or competing steps. Thereafter, novel strategies could be designed and constructed to further enhance BCAAs production. In addition, the substrate diversity of AHAIR, DHAD, and TA should be determined via mutagenesis or by replacing them with their isozymes with substrate specificity to realize the production of individual BCAAs. For example, transaminase TyrB from E. coli, which catalyzes only 2-ketoisocaproate to produce L-leucine, could replace the substrate-diverse transaminase TA in C. glutamicum to allocate more carbon source for the sole production of L-leucine [63].

\section{Regulation of BCAAs transporters}

The two-component transporter protein in C. glutamicum, BrnFE, transports BCAAs and L-methionine into the extracellular milieu, whereas BrnQ transports BCAAs into cells [83]. Complexes comprising BCAAs and the global regulatory factor Lrp bind to the interval sequence between lrp and brnFE to activate BrnFE expression [83, 84]. Therefore, regulating the expression of Lrp can regulate the BCAAs transport and further influence BCAAs production. For example, Lrp overexpressed in C. glutamicum ATCC13869 increased L-valine and L-isoleucine production by 16- and 8.9-fold, respectively [45]. Furthermore, overexpressed Lrp, BrnFE, AHAS, and AHAIR in C. glutamicum ATCC13869 $\triangle$ aceE $\triangle$ alaTAilvA has yielded $28.5 \mathrm{~g} / \mathrm{L} \mathrm{L}$-valine in shake flask [45]. Deleting BrnQ and overexpressing BrnFE increased the titer from 20.2 to $29.0 \mathrm{~g} / \mathrm{L}$ in a strain producing L-isoleucine [54], whereas co-expressed Lrp and BrnFE in C. glutamicum JHI3-156 increased L-isoleucine production by $63 \%$ in shaker flasks and by $72 \%$ in fed-batch fermentation [57] (Table 3).

Based on the above regulation mechanisms, the lrp$b r n E F$ regulation system has been engineered to establish a BCAAs biosensor that could convert specific concentrations of BCAAs into easily detectable YFP signals [85]. The BCAAs concentration in the biosensor was linear with fluorescence signal intensity, and strains producing abundant L-valine were screened by fluorescence activated cell sorting (FACs) [86]. The lrpbrnEF regulation system has been applied to dynamically regulate the metabolic pathway involved in producing the synthetic unnatural amino acid 4-hydroxyisoleucine (4-HIL) [87]. Subsequently, the promoter $\mathrm{P}_{\text {brnFE }}$ in the lrp-brnEF regulation system was modified to the stronger promoter $\mathrm{P}_{\text {brnFE }} \mathrm{N}$, which was used to regulate the transcription of L-isoleucine dioxygenase (IDO), that could convert L-isoleucine into 4-HIL in the presence of $\alpha$-KG and oxygen. Meanwhile, the supply of $\alpha-K G$ and oxygen was coordinately modulated via this regulation system, which finally produced $19.9 \mathrm{~g} / \mathrm{L}$ 4-HIL [88]. In general, regulating BCAAs transporter expression efficiently enhances BCAAs production. The lrp-brnEF regulation system can be used to establish biosensor to screen productive strains (Fig. 2a). First, BCAAs produced in the culture could bind to regulatory protein Lrp which under the regulation of $\mathrm{P}_{l r p}$. Then, the generated complex could activate the promoter $\mathrm{P}_{b r n F}$, which regulates the transcription of report gene such as $g f p, y f p$ and $r f p$. Detection of report protein could directly reflect the concentration of intracellular BCAAs. This biosensor system might be applied for screening BCAAs high-productive strains. In addition, brnFE-lrp system could also be used for establishing dynamic metabolic network to increase the biosynthesis of value-added compounds. As shown in Fig. 2b, different metabolites bind to corresponding regulatory proteins to activate or inhibit the expression of downstream genes. The cascade system regulated by the concentrations of metabolites could realize the dynamic regulation of target compounds production. Meanwhile, the construction of dynamic regulation network could realize the optimal distribution of BCAAs in cell growth and products biosynthesis.

\section{Bioinformatics analysis of strains producing BCAAs}

Analysis of strains producing BCAAs using genomics, transcriptomics, proteomics, and metabolomics could reveal significant information for further host modification to maximize BCAAs production. A comparison of intracellular metabolites and BCAAs production by wild-type C. glutamicum, C. glutamicum XV (producing L-valine), and C. glutamicum CP (producing L-leucine) [89] revealed a more active pentose phosphate pathway in the XV or CP strains than the wild type, indicating that these strains could produce more NADPH than the wild type. C. glutamicum XV and CP were obtained via multiple rounds of random mutagenesis [65], and these two strains are accessible at the China General Microbiological Culture Collection Center with the identifiers of CGMCC11425 (CP) and CGMCC 1.15672 (XV), respectively [89]. The transcription of most genes in L-valine and L-leucine biosynthetic pathways is up-regulated in the XV and CP strains [89]. A subsequent comparison of the three strains by time-series metabolomics identified 


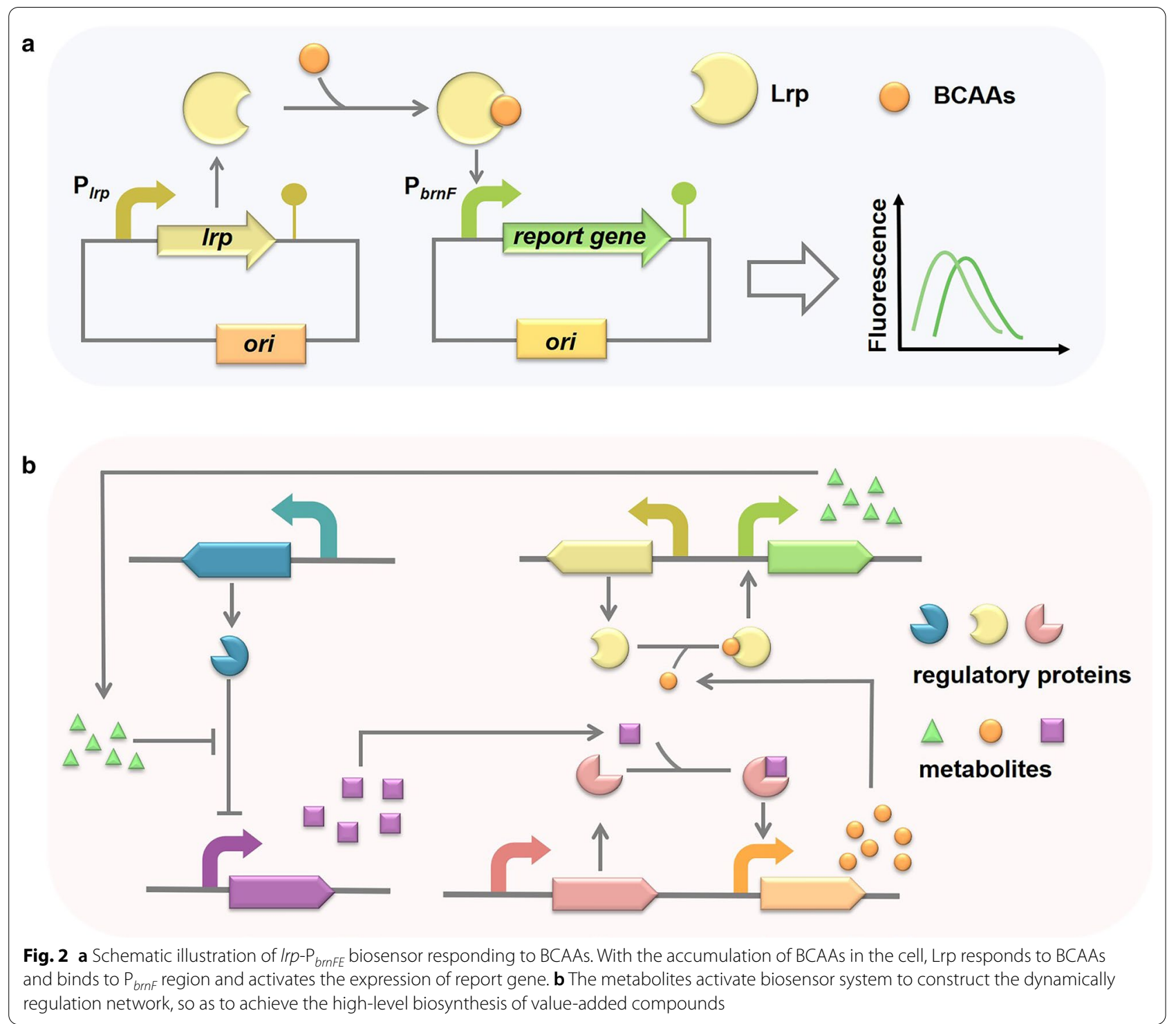

metabolic differences mainly found in central carbon metabolism and stress resistance. Corynebacterium glutamicum XV has evolved more pyruvate for L-valine synthesis and accumulated trehalose to resist environmental stress, whereas C. glutamicum CP has high membrane permeability that could improve the efficiency of extracellular L-leucine transport [90]. A comparison of transcriptomic and proteomic data from C. glutamicum VWB-1, an industrial L-valine producer, and wild type C. glutamicum ATCC13869 uncovered significantly different transcriptional levels of 1,155 genes and the abundance of 96 proteins between them [91]. Specifically, transcription of the $i l v B N, i l v C$, $i l v D$, and $i l v E$ genes crucial to the L-valine biosynthetic pathway was upregulated, whereas that of the $l e u B$ and $i l v A$ genes crucial to the L-leucine and L-isoleucine biosynthetic pathways was downregulated. Thus, the metabolic flux of L-valine pathway was enhanced, and the competing pathway was blocked to increase the yield of L-valine. Analysis of the C. glutamicum transcriptome uncovered the transcriptional attenuators, $\operatorname{trp} L, i l v L$, and $l e u L$, which are, respectively, involved in L-tryptophan, L-valine, and L-leucine production. This was the first use of transcriptome datasets to accurately describe attenuation locations and attenuator structures, and it laid a foundation to relieve the effects of attenuation and further improve BCAAs yield [30]. In general, C. glutamicum bioinformatics analysis has offered some explanations for elevated BCAAs production and some evidence to support the engineering strategies described above. In addition, bioinformatic 




Fig. 3 Biosynthetic pathways of BCAAs derivatives in C. glutamicum. The blue areas represent derivatives related to the L-isoleucine metabolic pathway, the green areas represent derivatives related to the L-valine metabolic pathway, and the pink areas represent derivatives related to the L-leucine metabolic pathway. ADH: alcohol dehydrogenase; PDH: pyruvate dehydrogenase; ACAT: Acetyl-CoA acetyltransferase; PhaB: acetoacetyl-CoA reductase; PhaC: poly(3-hydroxybutyrate) polymerase; PHBV: Poly(3-hydroxybutyrate-co-3-hydroxyvalerate); KDC: keto acid decarboxylase; IDO: isoleucine dioxygenase; ALDC: acetolactatedecarboxylase; SADH, secondary alcohol dehydrogenase

data could be applied to establish other regulation strategies that might enhance the production of BCAAs or their derivatives. Combining bioinformatics technology with synthetic biology has significant value for strain modification, which could provide a basis and guide the maximal yields of target compounds.

\section{Conclusions and perspectives}

Removing feedback inhibition and/or the transcriptional attenuation of some crucial enzymes is significant for enhancing BCAAs production. However, the lack of clarity about the underlying mechanisms prevented the complete elimination of feedback inhibition and transcriptional attenuation. Therefore, the crystal structures, molecular docking complexes, and mechanisms of feedback inhibition and/or the transcriptional attenuation of crucial enzymes were analyzed. With better understanding of the involved mechanisms, mutations that could induce a target enzyme to completely delete feedback inhibition and/or transcriptional attenuation could be rationally designed and introduced into target enzymes to address the problems of intermediates or low yields caused by BCAAs accumulation. The structural similarity of BCAAs precursors and the promiscuity of enzymes involved in BCAAs biosynthetic pathways resulted in the mixed production of three BCAAs, which complicated BCAAs separation and purification. The enzymes shared in three BCAAs biosynthetic pathways needed to be crystallized, and the catalytic mechanisms of different precursors required exploration. Thus, substrate-specific enzymes were created through directed mutagenesis and applied to the production of individual BCAAs. Construction of a computer algorithm-assisted metabolic network model might be an efficient and economical method of determining the rate-limiting points of BCAAs metabolic pathways. Thereafter, a series of modifications could be created to address the rate-limiting points and generate strains suitable for industrial-scale BCAAs production. Such strains might be used to biosynthesize BCAAs derivatives such as isobutyraldehyde [92], isobutanol [93], and 3-methyl-1-butanol [94], which share precursors with BCAAs (Fig. 3). Meanwhile, developing strains producing BCAAs might provide guidance for constructing other strains that could produce valuable compounds.

\section{Acknowledgements \\ Not applicable.}

\section{Authors' contributions}

YH conceived the topic. SY reviewed literature and prepared first draft manuscript. ZC, BZ and YH revised the manuscript. ZC reviewed and edited the content. All authors contributed to the article and approved the submitted version.

\section{Funding}

The authors would like to acknowledge financial support of the National Natural Science Foundation of China (Grant No. 21908007), the National Key R\&D Program of China (Grant No. 2019YFA0904104) and the Fundamental Research Funds for the Central Universities.

\section{Availability of data and materials}

Data sharing is not applicable to this article as no datasets were generated or analyzed during the current study. 


\section{Declarations}

Ethics approval and consent to participate

Not applicable.

\section{Consent for publication}

Not applicable.

\section{Competing interests}

The authors declare that they have no competing interests.

Received: 1 September 2021 Accepted: 11 December 2021

Published online: 24 December 2021

\section{References}

1. Wu G. Amino acids: metabolism, functions, and nutrition. Amino Acids. 2009:37:1-17

2. Wolfe RR. Branched-chain amino acids and muscle protein synthesis in humans: myth or reality? J Int Soc Sport Nutr. 2017;14:30-30.

3. Trushina EN, Vybornov VD, Riger NA, Mustafina OK, Solntseva TN, Timonin AN, Zilova IS, Radzhabkadiev RM. The efficiency of branched chain aminoacids (BCAA) in the nutrition of combat sport athletes. Vopr Pitan. 2019;88:48-56.

4. Park JG, Tak WY, Park SY, Kweon YO, Jang SY, Lee YR, Bae SH, Jang JY, Kim DY, Lee JS, et al. Effects of branched-chain amino acids (BCAAs) on the progression of advanced liver disease: a Korean nationwide, multicenter retrospective, observational, cohort study. Medicine. 2017;96:e6580.

5. Nie C, He T, Zhang W, Zhang G, Ma X. Branched chain amino acids: beyond nutrition metabolism. Int J Mol Sci. 2018;19:954.

6. Park JH, Lee SY. Fermentative production of branched chain amino acids: a focus on metabolic engineering. Appl Microbiol Biotechnol. 2010;85:491-506.

7. BCAA market size is estimated to grow with a CAGR of $3.8 \%$ during 2021-2026 with top countries data. 360 Research Reports 2021.

8. Branched chain amino acids - A global market overview 2021. Research and markets 2021

9. Global BCAA market research report 2020. 360 Research Reports 2020

10. Eggeling L, Morbach S, Sahm H. The fruits of molecular physiology: engineering the l-isoleucine biosynthesis pathway in Corynebacterium glutamicum. J Biotechnol. 1997;56:167-82.

11. Suzuki M, Sato T, Kurose A, Shirai H, Hanabusa K. New low-molecular weight gelators based on L-valine and L-isoleucine with various terminal groups. Tetrahedron Lett. 2005;46:2741-5.

12. Yamamoto K, Tsuchisaka A, Yukawa H. Branched-chain amino acids. Adv Biochem Eng Biotechnol. 2017;159:103-28.

13. Kalinowski J, Bathe B, Bartels D, Bischoff N, Bott M, Burkovski A, Dusch N, Eggeling L, Eikmanns BJ, Gaigalat L, et al. The complete Corynebacterium glutamicum ATCC 13032 genome sequence and its impact on the production of L-aspartate-derived amino acids and vitamins. J Biotechnol. 2003;104:5-25.

14. Park JH, Lee SY. Towards systems metabolic engineering of microorganisms for amino acid production. Curr Opin Biotechnol. 2008;19:454-60.

15. Hermann T. Industrial production of amino acids by coryneform bacteria. J Biotechnol. 2003;104:155-72.

16. Becker J, Zelder O, Häfner S, Schröder H, Wittmann C. From zero to hero-design-based systems metabolic engineering of Corynebacterium glutamicum for L-lysine production. Metab Eng. 2011;13:159-68.

17. Eggeling I, Cordes C, Eggeling L, Sahm H. Regulation of acetohydroxy acid synthase in Corynebacterium glutamicum during fermentation of a-ketobutyrate to L-isoleucine. Appl Microbiol Biotechnol. 1987;25:346-51.

18. Guo Y, Han M, Xu J, Zhang W. Analysis of acetohydroxyacid synthase variants from branched-chain amino acids-producing strains and their effects on the synthesis of branched-chain amino acids in Corynebacterium glutamicum. Protein Expr Purif. 2015;109:106-12.

19. Morbach S, Sahm H, Eggeling L. Use of feedback-resistant threonine dehydratases of Corynebacterium glutamicum to increase carbon flux towards L-isoleucine. Appl Environ Microbiol. 1995;61:4315-20.
20. Pátek M, Krumbach K, Eggeling L, Sahm H. Leucine synthesis in Corynebacterium glutamicum: enzyme activities, structure of leuA, and effect of leuA inactivation on lysine synthesis. Appl Environ Microbiol. 1994;60:133-40.

21. Shiio I, Miyajima R. Concerted inhibition and its reversal by end products of aspartate kinase in Brevibacterium flavum. J Biochem. 1969:65:849-59.

22. Wang $X$. Strategy for improving L-isoleucine production efficiency in Corynebacterium glutamicum. Appl Microbiol Biotechnol. 2019;103:2101-11.

23. Duggleby RG. Domain relationships in thiamine diphosphate-dependent enzymes. Acc Chem Res. 2006;39:550-7.

24. Chipman D, Barak Z, Schloss JV. Biosynthesis of 2-aceto-2-hydroxy acids: acetolactate synthases and acetohydroxyacid synthases. Biochimica et Biophysica Acta. 1998;1385:401-19.

25. Weinstock O, Sella C, Chipman DM, Barak Z. Properties of subcloned subunits of bacterial acetohydroxy acid synthases. J Bacteriol. 1992:174:5560-6

26. Chipman DM, Duggleby RG, Tittmann K. Mechanisms of acetohydroxyacid synthases. Curr Opin Chem Biol. 2005;9:475-81.

27. Elisáková V, Pátek M, Holátko J, Nesvera J, Leyval D, Goergen JL, Delaunay S. Feedback-resistant acetohydroxy acid synthase increases valine production in Corynebacterium glutamicum. Appl Environ Microbiol. 2005; 71:207-13.

28. Gedi V,Yoon M-Y. Bacterial acetohydroxyacid synthase and its inhibitors-a summary of their structure, biological activity and current status. FEBS J. 2012;279:946-63.

29. Morbach S, Junger C, Sahm H, Eggeling L. Attenuation control of ilVBNC in Corynebacterium glutamicum: evidence of leader peptide formation without the presence of a ribosome binding site. J Biosci Bioeng. 2000:90:501-7.

30. Neshat A, Mentz A, Rückert C, Kalinowski J. Transcriptome sequencing revealed the transcriptional organization at ribosome-mediated attenuation sites in Corynebacterium glutamicum and identified a novel attenuator involved in aromatic amino acid biosynthesis. J Biotechnol. 2014;190:55-63.

31. Zhao $Y$, Niu $C$, Wen $X, X i Z$. The minimum activation peptide from ilvH can activate the catalytic subunit of AHAS from different species. ChemBioChem. 2013;14:746-52.

32. Leyval D, Uy D, Delaunay S, Goergen JL, Engasser JM. Characterisation of the enzyme activities involved in the valine biosynthetic pathway in a valine-producing strain of Corynebacterium glutamicum. J Biotechnol. 2003; 104:241-52

33. Vogt M, Haas S, Klaff S, Polen T, Eggeling L, Ooyen JV, Bott M. Pushing product formation to its limit: metabolic engineering of Corynebacterium glutamicum for L-leucine overproduction. Metab Eng. 2014:22:40-52.

34. Guo Y, Han M, Yan W, Xu J, Zhang W. Generation of branched-chain amino acids resistant Corynebacterium glutamicum acetohydroxy acid synthase by site-directed mutagenesis. Biotechnol Bioprocess Eng. 2014;19:456-67.

35. Wada M, Hijikata N, Aoki R, Takesue N, Yokota A. Enhanced valine production in Corynebacterium glutamicum with defective $\mathrm{H}^{+}$-ATPase and C-terminal truncated acetohydroxyacid synthase. Biosci Biotechnol Biochem. 2008:72:2959-65.

36. Jeon AJ, Song BC, Lee JH, Kim JH, Kim HW. Acetohydroxy acid synthase variant, microorganism comprising the same, and method of producing L-branched-chain amino acid using the same. United States. US20200080071A1. 2020

37. Liu Y, Li Y, Wang X. Acetohydroxyacid synthases: evolution, structure, and function. Appl Microbiol Biotechnol. 2016;100:8633-49.

38. Steinmetz A, Vyazmensky M, Meyer D, Barak Z, Golbik R, Chipman DM, Tittmann K. Valine 375 and Phenylalanine 109 Confer affinity and specificity for pyruvate as donor substrate in acetohydroxy acid synthase isozyme II from Escherichia coli. Biochemistry. 2010;49:5188-99.

39. Wieschalka S, Blombach B, Eikmanns BJ. Engineering Corynebacterium glutamicum for the production of pyruvate. Appl Microbiol Biotechnol. 2012;94:449-59.

40. Blombach B, Schreiner ME, Holátko J, BartekT, Oldiges M, Eikmanns BJ. L-Valine production with pyruvate dehydrogenase complex-deficient Corynebacterium glutamicum. Appl Environ Microbiol. 2007;73:2079-84. 
41. Blombach B, Schreiner ME, Bartek T, Oldiges M, Eikmanns BJ. Corynebacterium glutamicum tailored for high-yield L-valine production. Appl Microbiol Biotechnol. 2008;79:471-9.

42. Buchholz J, Schwentner A, Brunnenkan B, Gabris C, Grimm S, Gerstmeir R, Takors R, Eikmanns BJ, Blombach B. Platform engineering of Corynebacterium glutamicum with reduced pyruvate dehydrogenase complex activity for improved production of L-lysine, L-valine, and 2-ketoisovalerate. Appl Environ Microbiol. 2013;79:5566-75.

43. Wang Y, Shi K, Chen P, Zhang F, Xu J, Zhang W. Rational modification of the carbon metabolism of Corynebacterium glutamicum to enhance L-leucine production. J Ind Microbiol Biotechnol. 2020;47:485-95.

44. Ma Y, Cui Y, Du L, Liu X, Xie X, Chen N. Identification and application of a growth-regulated promoter for improving L-valine production in Corynebacterium glutamicum. Microb Cell Fact. 2018;17:185.

45. Chen C, Li Y, Hu J, Dong X, Wang X. Metabolic engineering of Corynebacterium glutamicum ATCC13869 for L-valine production. Metab Eng. 2015;29:66-75.

46. Blombach B, Arndt A, Auchter M, Eikmanns BJ. L-Valine production during growth of pyruvate dehydrogenase complex-deficient Corynebacterium glutamicum in the presence of ethanol or by inactivation of the transcriptional regulator SugR. Appl Environ Microbiol. 2009;75:1197-200.

47. Schwentner A, Feith A, Münch E, Busche T, Rückert C, Kalinowski J, Takors $\mathrm{R}$, Blombach B. Metabolic engineering to guide evolution- creating a novel mode for L-valine production with Corynebacterium glutamicum. Metab Eng. 2018:47:31-41.

48. Han G, Xu N, Sun X, Chen J, Chen C, Wang Q. Improvement of L-valine production by atmospheric and room temperature plasma mutagenesis and high-throughput screening in Corynebacterium glutamicum. ACS Omega. 2020;5:4751-8.

49. Radmacher E, Vaitsikova A, Burger U, Krumbach K, Sahm H, Eggeling L. Linking central metabolism with increased pathway flux: L-valine accumulation by Corynebacterium glutamicum. Appl Environ Microbiol. 2002;68:2246-50

50. Marienhagen J, Eggeling L. Metabolic function of Corynebacterium glutamicum aminotransferases AlaT and AvtA and impact on L-valine production. Appl Environ Microbiol. 2008;74:7457-62.

51. Holátko J, Elisáková V, Prouza M, Sobotka M, Nesvera J, Pátek M. Metabolic engineering of the L-valine biosynthesis pathway in Corynebacterium glutamicum using promoter activity modulation. J Biotechnol. 2009:139:203-10

52. Hasegawa S, Uematsu K, Natsuma Y, Suda M, Hiraga K, Jojima T, Inui M, Yukawa $\mathrm{H}$. Improvement of the redox balance increases L-valine production by Corynebacterium glutamicum under oxygen deprivation conditions. Appl Environ Microbiol. 2012;78:865-75.

53. Hasegawa S, Suda M, Uematsu K, Natsuma Y, Hiraga K, Jojima T, Inui M, Yukawa H. Engineering of Corynebacterium glutamicum for high-yield L-valine production under oxygen deprivation conditions. Appl Environ Microbiol. 2013;79:1250-7.

54. Xie X, Xu L, Shi J, Xu Q, Chen N. Effect of transport proteins on L-isoleucine production with the L-isoleucine-producing strain Corynebacterium glutamicum YILW. J Ind Microbiol Biotechnol. 2012:39:1549-56.

55. Ma W, Wang J, Li Y, Hu X, Shi F, Wang X. Enhancing pentose phosphate pathway in Corynebacterium glutamicum to improve L-isoleucine production. Biotechnol Appl Biochem. 2016;63:877-85.

56. Ma W, Wang J, Li Y, Yin L, Wang X. Poly(3-hydroxybutyrate-co-3-hydroxyvalerate) co-produced with L-isoleucine in Corynebacterium glutamicum WM001. Microb Cell Factories. 2018;17:93.

57. Yin L, Shi F, Hu X, Chen C, Wang X. Increasing L-isoleucine production in Corynebacterium glutamicum by overexpressing global regulator Lrp and two-component export system BrnFE. J Appl Microbiol. 2013;114:1369-77.

58. Vogt M, Krumbach K, Bang W-G, Ooyen JV, Noack S, Klein B, Bott M, Eggeling L. The contest for precursors: channelling L-isoleucine synthesis in Corynebacterium glutamicum without byproduct formation. Appl Microbiol Biotechnol. 2015;99:791-800.

59. Shi F, Li K, Huan X, Wang X. Expression of NAD(H) kinase and glucose6-phosphate dehydrogenase improve NADPH supply and L-isoleucine biosynthesis in Corynebacterium glutamicum ssp. lactofermentum. Appl Biochem Biotechnol. 2013;171:504-21.

60. Dong $X$, Zhao Y, Hu J, Li Y, Wang X. Attenuating L-lysine production by deletion of $d d h$ and lysE and their effect on L-threonine and L-isoleucine production in Corynebacterium glutamicum. Enzyme Microb Technol. 2016;93-94:70-8.

61. Wang J, Wen B, Wang J, Xu Q, Zhang C, Chen N, Xie X. Enhancing L-isoleucine production by thr $A B C$ overexpression combined with alaT deletion in Corynebacterium glutamicum. Appl Biochem Biotechnol. 2013;171:20-30.

62. Wang Y, Zhang F, Xu J, Zhang W, Chen X, Liu L. Improvement of L-leucine production in Corynebacterium glutamicum by altering the redox flux. Int J Mol Sci. 2020;2019:20.

63. Feng L, Xu J, Zhang W. Improved L-leucine production in Corynebacterium glutamicum by optimizing the aminotransferases. Molecules. 2018:23:2102.

64. Huang $Q$, Liang $L$, Wu W, Wu S, Huang J. Metabolic engineering of Corynebacterium glutamicum to enhance L-leucine production. Afr J Biotechnol. 2017;16:1048-60.

65. Ma Y, Chen Q, Cui Y, Du L, Shi T, Xu Q, Ma Q, Xie X, Chen N. Comparative genomic and genetic functional analysis of industrial L-leucine- and L-valine-producing Corynebacterium glutamicum strains. J Microbiol Biotechnol. 2018;28:1916-27.

66. Gerstmeir R, Wiegrabe I.Feedback-resistant alpha-isopropylmalate synthases. United States. US009347048B2. 2016

67. Lee JH, Song BC, Jeon AJ, Kim JH, Kim HW. A novel isopropylmalate synthase variant and a method of producing L-leucine using the same. United States. US20200032305A1. 2020

68. Duesseldorf B, Eggeling L, Sahm H. Production of L-isoleucine by means of recombinant microorganisms with deregulated threonine dehydratase. United Stataes. US006107063A. 2000

69. Yin L, Zhao J, Chen C, Hu X, Wang X. Enhancing the carbon flux and NADPH supply to increase L-isoleucine production in Corynebacterium glutamicum. Biotechnol Bioprocess Eng. 2014;19:132-42.

70. Yin L, Hu X, Xu D, Ning J, Chen J, Wang X. Co-expression of feedbackresistant threonine dehydratase and acetohydroxy acid synthase increase L-isoleucine production in Corynebacterium glutamicum. Metab Eng. 2012;14:542-50.

71. Dong $X$, Zhao $Y$, Zhao J, Wang $X$. Characterization of aspartate kinase and homoserine dehydrogenase from Corynebacterium glutamicum IWJ001 and systematic investigation of L-isoleucine biosynthesis. J Ind Microbiol Biotechnol. 2016:43:873-85.

72. Guo Y, Xu J, Han M, Zhang W. Generation of mutant threonine dehydratase and its effects on isoleucine synthesis in Corynebacterium glutamicum. World J Microbiol Biotechnol. 2015;31:1369-77.

73. Hou X, Ge X, Wu D, Qian H, Zhang W. Improvement of L-valine production at high temperature in Brevibacterium flavum by overexpressing ilvEBN $C$ genes. J Ind Microbiol Biotechnol. 2012;39:63-72.

74. Petit C, Kim Y, Lee S-K, Brown J, Larsen E, Ronning DR, Suh J-W, Kang C-M. Reduction of feedback inhibition in homoserine kinase (ThrB) of Corynebacterium glutamicum enhances L-threonine biosynthesis. ACS Omega. 2018;3:1178-86.

75. Wang X, Zhang H, Quinn PJ. Production of L-valine from metabolically engineered Corynebacterium glutamicum. Appl Microbiol Biotechnol. 2018:102:4319-30.

76. Börmann ER, Eikmanns BJ, Sahm H. Molecular analysis of the Corynebacterium glutamicum gdh gene encoding glutamate dehydrogenase. Mol Microbiol. 1992;6:317-26.

77. Kabus A, Georgi T, Wendisch VF, Bott M. Expression of the Escherichia colipnt $A B$ genes encoding a membrane-bound transhydrogenase in Corynebacterium glutamicum improves L-lysine formation. Appl Microbiol Biotechnol. 2007:75:47-53.

78. Li Y, Cong H, Liu B, Song J, Sun X, Zhang J, Yang Q. Metabolic engineering of Corynebacterium glutamicum for methionine production by removing feedback inhibition and increasing NADPH level. Antonie Van Leeuwenhoek. 2016:109:1185-97.

79. Ying W. NAD $/ \mathrm{NADH}$ and $N A D P^{+} / \mathrm{NADPH}$ in cellular functions and cell death: regulation and biological consequences. Antioxid Redox Signal. 2008;10:179-206

80. Garavaglia S, Raffaelli N, Finaurini L, Magni G, Rizzi M. A novel fold revealed by Mycobacterium tuberculosis NAD kinase, a key allosteric enzyme in NADP biosynthesis. J Biol Chem. 2004;279:40980-6.

81. BartekT, Blombach B, Zönnchen E, Makus P, Lang S, Eikmanns BJ, Oldiges $M$. Importance of NADPH supply for improved L-valine formation in Corynebacterium glutamicum. Biotechnol Prog. 2010;26:361-71. 
82. Moritz B, Striegel K, Graaf AA, Sahm H. Kinetic properties of the glucose-6-phosphate and 6-phosphogluconate dehydrogenases from Corynebacterium glutamicum and their application for predicting pentose phosphate pathway flux in vivo. Eur J Biochem. 2000;267:3442-52.

83. Lange C, Mustafi N, Frunzke J, Kennerknecht N, Wessel M, Bott M, Wendisch VF. Lrp of Corynebacterium glutamicum controls expression of the brnFE operon encoding the export system for I-methionine and branched-chain amino acids. J Biotechnol. 2012;158:231-41.

84. Kennerknecht N, Sahm H, Yen M-R, Pátek M, Saier MH Jr, Eggeling L. Export of L-isoleucine from Corynebacterium glutamicum: a twogene-encoded member of a new translocator family. J Bacteriol. 2002;184:3947-56.

85. Mustafi N, Grünberger A, Kohlheyer D, Bott M, Frunzke J. The development and application of a single-cell biosensor for the detection of L-methionine and branched-chain amino acids. Metab Eng. 2012;14:449-57.

86. Mahr R, Gätgens C, Gätgens J, Polen T, Kalinowski J, Frunzke J. Biosensordriven adaptive laboratory evolution of L-valine production in Corynebacterium glutamicum. Metab Eng. 2015;32:184-94.

87. Zhang C, Li Y, Ma J, Liu Y, He J, Li Y, Zhu F, Meng J, Zhan J, Li Z, et al. High production of 4-hydroxyisoleucine in Corynebacterium glutamicum by multistep metabolic engineering. Metab Eng. 2018;49:287-98.

88. Tan S, Shi F, Liu H, Yu X, Wei S, Fan Z, Li Y. Dynamic control of 4-Hydroxyisoleucine biosynthesis by modified L-isoleucine biosensor in recombinant Corynebacterium glutamicum. ACS Synth Biol. 2020;9:2378-89.

89. Ma Y, Ma Q, Cui Y, Du L, Xie X, Chen N. Transcriptomic and metabolomics analyses reveal metabolic characteristics of L-leucine- and L-valineproducing Corynebacterium glutamicum mutants. Ann Microbiol. 2019:69:457-68

90. Ma Q, Mo X, Zhang Q, Hou Z, Tan M, Xia L, Sun Q, Xie X, Chen N. Comparative metabolomic analysis reveals different evolutionary mechanisms for branched-chain amino acids production. Bioprocess Biosyst Eng. 2020:43:85-95.

91. Zhang H, Li Y, Wang C, Wang X. Understanding the high L-valine production in Corynebacterium glutamicum VWB-1 using transcriptomics and proteomics. Sci Rep. 2018;8(1):1-8.

92. Rodriguez GM, Atsumi S. Isobutyraldehyde production from Escherichia coli by removing aldehyde reductase activity. Microb Cell Factories. 2012;11:90.

93. Atsumi S, Hanai T, Liao JC. Non-fermentative pathways for synthesis of branched-chain higher alcohols as biofuels. Nature. 2008;451:86-9.

94. Connor MR, Cann AF, Liao JC. 3-Methyl-1-butanol production in Escherichia coli: random mutagenesis and two-phase fermentation. Appl Microbiol Biotechnol. 2010;86:1155-64.

\section{Publisher's Note}

Springer Nature remains neutral with regard to jurisdictional claims in published maps and institutional affiliations.

Ready to submit your research? Choose BMC and benefit from:

- fast, convenient online submission

- thorough peer review by experienced researchers in your field

- rapid publication on acceptance

- support for research data, including large and complex data types

- gold Open Access which fosters wider collaboration and increased citations

- maximum visibility for your research: over $100 \mathrm{M}$ website views per year

At BMC, research is always in progress.

Learn more biomedcentral.com/submissions 